\title{
Mechanical analysis of composite ribbed shell under dynamical loads
}

\author{
Y.Z. Chang ${ }^{1, a}$, T. Feng ${ }^{1, b}$ and Sh. L. Meng ${ }^{2, c}$ \\ ${ }^{1}$ College of civil engineerin g, Xi'an University of Architecture \& Technology, Xi'an, 710055, China \\ ${ }^{2}$ Chang farce culture holding co., Xu Chang, 461000, China \\ a changyz@xauat.edu.cn, ${ }^{b}$ Fengting@xauat.edu.cn, ${ }^{\mathrm{C}}$ Mengshl@xauat.edu.cn
}

Keywords: composite ribbed shell; step load; seismic analysis; strength failure; dynamic stability Abstract. Spherical composite ribbed shell is made of thin reinforced concrete shell and composite ribs, which has many advantages such as large span, high rigidity, and large bearing capacity and low cost. It is one of the urgent issues to considering the mechanical performance under dynamic loading. Based on nonlinear finite element theory, a numerical calculation model is built, and then the dynamic response of composite ribbed shell under step load and seismic wave are respectively discussed. The results shows: under the vertical step load, a positive symmetric deformation appeared in unstable status; under horizontal step loads, an anti symmetric deformation emerged. While as the seismic wave was exerting, structural damage caused by thin concrete shell damage and plastic deformation development, namely it was the synthetic action result of structural stiffness weaken and P- $\Delta$ effect from geometric nonlinear, so structure damage was the comprehensive effect of strength failure and dynamic instable.

\section{Introduction}

In the last century, reinforced concrete shell structure is promoted because of its advantages, such as novel structure forms, excellent building performance, and cheap materials cost, good durability, low maintenance costs. But the complicated construction technology and higher construction costs greatly prevented the development of reinforced concrete shells. Recent years, many scholars put forward different composite structures [1-4], such as the sheet space structure system, the composite reticulated shell structure, arch-supported reticulated shell and mixed reticulated shell. The long-span steel - concrete shell roof system proposed by Hong Kong Polytechnic University [5], in which such things similar to reticulated boxes were connected by bolts and concrete were poured in, this roof system did not need templates any more, the splicing units and pouring concrete formed a shell together. The steel-concrete composite ribbed shell is composed of composite ribs and reinforced concrete shell, the former makes full use of the steel tensile properties and the concrete compressive properties, the latter can provide higher membrane stress. During the structure construction process, the U-shaped steel ribs can be used as the templates of casting thin shell concrete, these can shorten the construction period and reduce the project cost [6]. All the researches are focused on the static characteristics in last five years, while there are little references about dynamic response. China is located in an earthquake zone, there is more seismic activity, it has an important significance to make the dynamic instability analysis. Therefore, the dynamic responses under step loadings and seismic actions are discussed in detailed, in which including the deformation and internal forces. All these can provide references for further structure system research.

\section{The Numerical Calculation Model}

Referred to reticulated steel shell, spherical composite ribbed shell is divided into 14 same arc length parts along orthogonal direction, the composite ribs are arranged, the rib grid is spaced about $3-4 \mathrm{~m}$. This can use composite ribs as pouring concrete templates for composite ribs and the thin concrete shell above. The geometric model and the arrangement of composite ribs are shown in Fig.1 and Fig.2 respectively. 

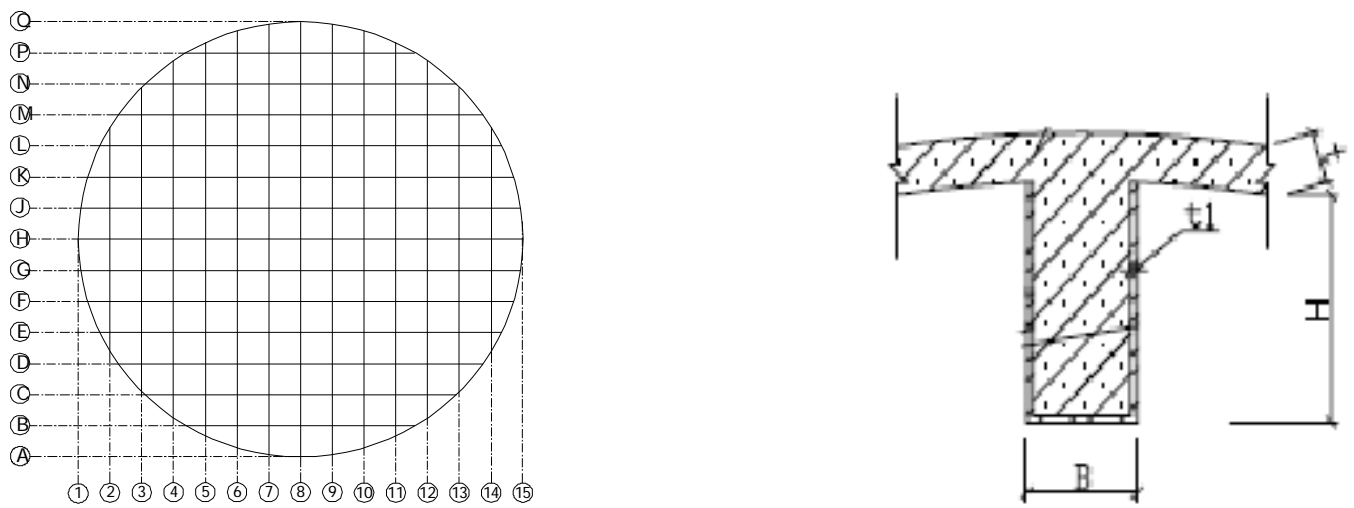

Fig. 1 the geometry model of composite shell Fig. 2 connection between composite ribs and thin shell

Considering elastic-plastic material, Kent - Park constitutive model for concrete is adopted, while for steel a two line elastic hardening model is used, the concrete is C30, while the steel is HRB235, the elastic modulus of steel $\mathrm{E}$ is $2.06 \times 10^{5} \mathrm{~N} / \mathrm{mm}^{2}$, the Poisson's ratio is 0.3 , the density is $7800 \mathrm{~kg} / \mathrm{m}^{3}$. While the steel is HRB235, the elastic modulus of concrete is $3.0 \times 10^{4} \mathrm{~N} / \mathrm{mm}^{2}$, the Poisson's ratio is 0.2 , the density is $2500 \mathrm{~kg} / \mathrm{m}^{3}$.

All node freedoms in shell boundary were limited, namely the fixed boundary conditions. BEAM188 was used to simulate the composite ribs, and user defined cross-section method is used, in which concrete and steel nonlinear properties were considered, SHELL181 is used to simulate the reinforced concrete shell. SHELL181 has four nodes, each node has six degrees of freedom, those are displacements and rotations about $\mathrm{X}, \mathrm{Y}, \mathrm{Z}$ axis. In order to facilitate simulation of reinforced concrete shell, the reinforced concrete shell is equivalent to several layer, the reinforced steel is equivalent to reinforced layer.

\section{Dynamic Analysis under Step Loads}

In this paper, a numerical calculation model was established with a span $60 \mathrm{~m}$, span ratio $\mathrm{f} / \mathrm{L} 1 / 5$, point fixed along all edges, the division frequency number 7 . The initial static load was $2 \mathrm{KN} / \mathrm{m} 2$ by considering the structure gravity, all external loads were acted on the nodes, structural damping and initial geometric imperfections were not considered, the large element deformation and large rotation were considered.

\section{Elastic-plastic dynamic stability under vertical step load}

In order to obtain the critical dynamic buckling load, the trial-error method was adopted and nonlinear material, geometric nonlinearity and structure damping effect are considered. Through improving the amplitude of vertical step load, the dynamic response was observed as in Fig.3. For the dynamic instability was very sensitive to load disturbance, the vertical symmetrical deformation was the main structural damage shape in which the vertical displacement contributed more than others.

From the Fig.4, it can be seen that as the loads increasing gradually, the structure stiffness decreased gradually, because of the nonlinear interaction between internal forces and displacement, the structural stiffness losing leaded to the local shell bearing capacity decreasing, motion acceleration induced, all these caused structure to be a present dynamic response sensitive system. Finally it became a movement system as the structure stiffness losing.

\section{Elastic-plastic dynamic stability under horizontal step loads}

In order to investigate the horizontal step load, the acceleration amplitude increment was set as $0.1 \mathrm{~g}$. As the input loads increasing, the dynamic response tended to be larger among which the maximum displacements became greater as the time past, such as horizontal step loads amplitudes were $13.8 \mathrm{~g}$ and $13.9 \mathrm{~g}$. The maximum displacements at $0.5 \mathrm{~s}$ were $194.2 \mathrm{~mm}$ and $201.4 \mathrm{~mm}$ respectively. 

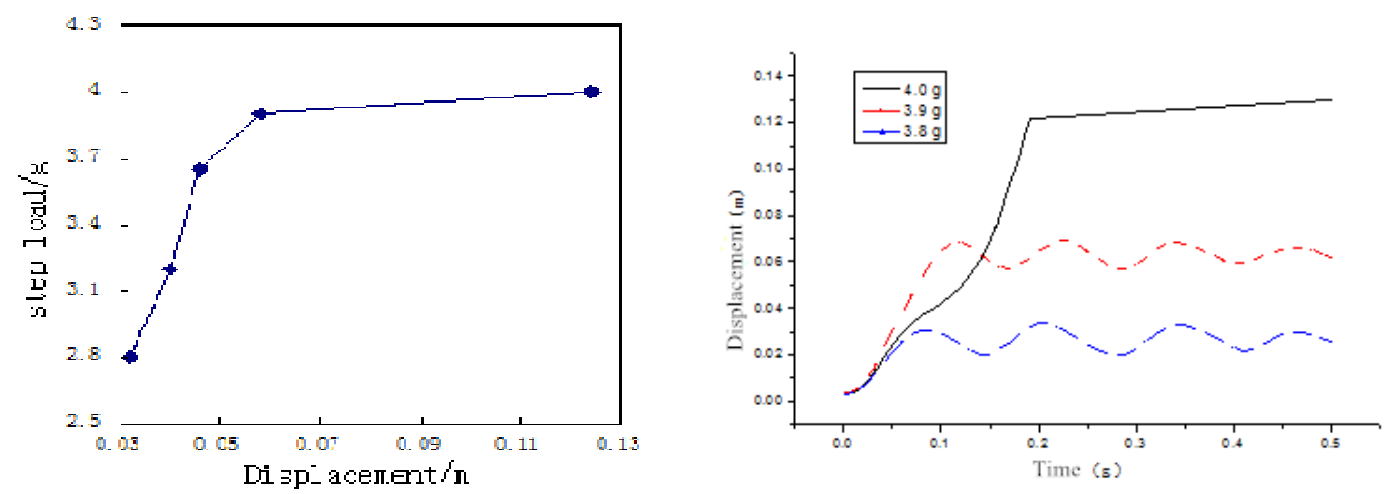

Fig. 3 curve of acceleration amplitude and displacement Fig.4 curve of max displacement and time
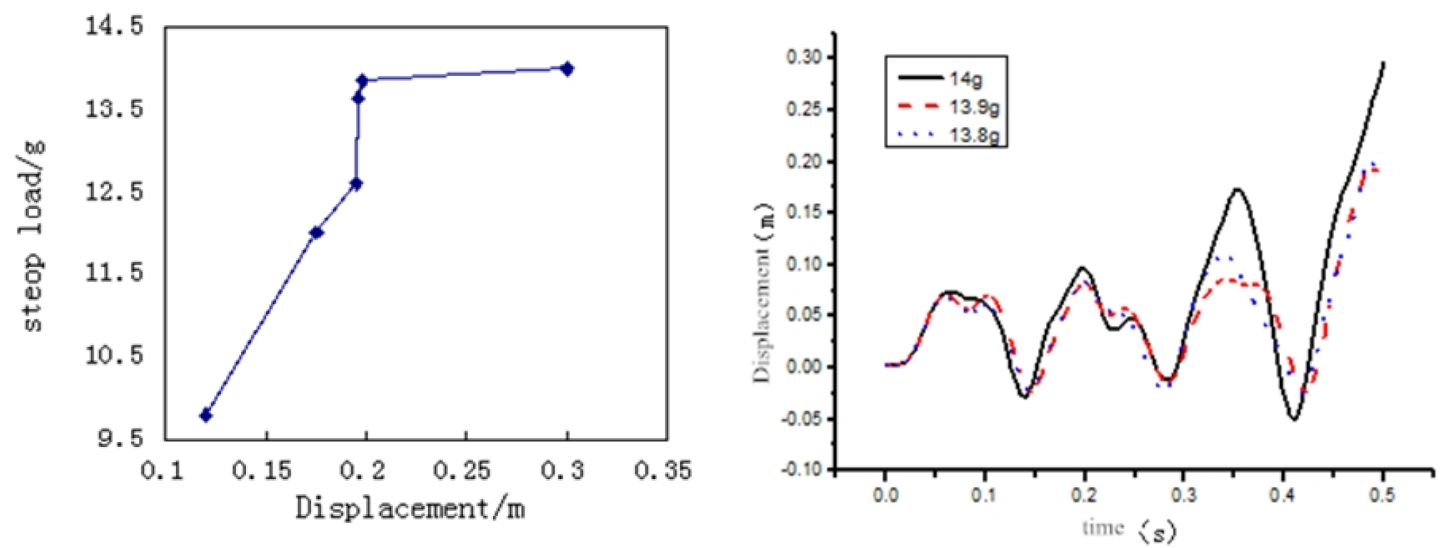

Fig.5 curve of acceleration and max displacement Fig.6 curve of max displacement and time

Before entering the unstable vibration phase, there was a substantial state existing a long time as in Fig.5 and Fig.6, structural stiffness had greatly weakened because of the shape change, which make the original form can no longer maintained, the displacement increased gradually.

At the same time under the horizontal step load, the deformation was ant symmetric in elastic state, the structure deformations between vertical direction and horizontal direction remain coupling, but the deformation in horizontal direction was more obvious. The warp deformation appeared in the edge of unconstrained concrete shell, the larger displacements arose in the main ribs paralleled with the load direction and surrounding strip area, the maximum displacement emerged at the edge area near the main rib, while the ones was smaller in the other main rib that vertical to losing direction.

\section{Dynamical performance under seismic loading}

In order to study structural seismic response, a spherical composite ribbed shell model was made, in which the span was $60 \mathrm{~m}$ and $80 \mathrm{~m}$, the span ratio was $1 / 5$ and $1 / 7$, the supporting condition was fixed along the edges, the frequency number was 7 , the geometry and material nonlinear analysis were considered for seismic analysis.

Maximum displacement of $31.0 \mathrm{~mm}$ arose in $3.58 \mathrm{~s}$, when the amplitude was added to $2.55 \mathrm{~g}$, the structural response increased than before, the equilibrium position shift down, when up to $2.65 \mathrm{~g}$, the deformation increased to the maximum, the shell geometry was further destroyed, and the plastic area expanded, the stiffness decreased, the structure had been unable, many cracks emerged in the concrete shell near the second segment edge, then the structure loss its stability quickly. When the acceleration amplitude was large enough, the structural deformation expanded, the stress state was destructed, composite ribbed shell can no longer bear gravity loads. 

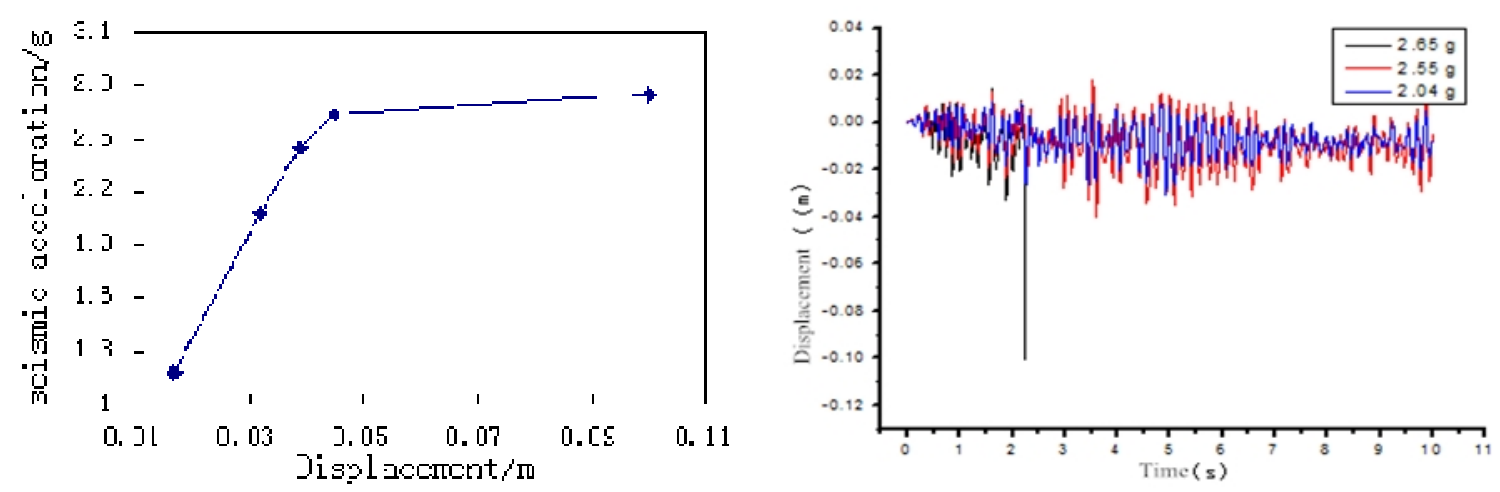

Fig.7 curve of acceleration and max displacement Fig.8 curve of max displacement and time

From the instable deformation graph Fig.7 and Fig.8, there was a serious coupling in the vertical and horizontal displacement of the whole structure, large deformations appeared in both the vertical and horizontal, then a greater cyclic deformation emerged in the edge of the second segment region. The structural plastic development degree was very small as in unstable, which showed, the geometric nonlinear had great influence on the dynamic stability. The instability was caused by structural stiffness weaken and structural deformation,

\section{Conclusion}

The dynamic performance of steel concrete composite ribbed shell is studied in this paper, the stability under step load and seismic loads is researched, the following conclusions are obtained.

1) Dynamic analysis under step loads showed, the larger the acceleration amplitude, the greater the structural dynamic response. Under vertical step load, the positive symmetric deformation arose as the structure lost its stability. While under horizontal step loads, the deformation was anti symmetric. The dynamic stability critical load increased with the span ratio increasing. the dynamic stability critical force was reduced with the span reduced..

2) Seismic analysis showed, when the peak acceleration was small, the structure is in the elastic vibration, when the acceleration amplitude was large enough, the shell stress state was damaged, the structure displacement increased suddenly, a number of cracks emerged in the concrete shell edge segments, then the structure collapsed quickly. When the structure losses its stability, the plastic development was very small, which showed that geometric nonlinear had great influence on the structure dynamic stability, the instability was induced by the stiffness weaken and P- $\square$ effects, the structure instability was comprehensive results of strength failure and dynamic instability.

\section{Acknowledgements}

This work was supported by the National Youth Fund Project (Grant No.51308443) and Scientific research project of Shaanxi Educational Committee (Grant No. 15JK1384).

\section{References}

[1] C.Z. Liu and H.L Zhao, Journal of southeast university, 28(1998), 75-81 in Chinese.

[2] Y. Zhao and S.L. Dong, Journal of Space Structure, 1(1994), 17-25 in Chinese..

[3] Z.Y. Shen and Li Y.Q, Journal of Space Structure, 2(1996), 25-29 in Chinese..

[4] Y Kong and F. H Dai, Journal of guizhou university of technology, 31(2002), 51-59.

[5] H.T. Wong and J.G Teng, Experimental Techniques, 27(2003), 21-27.

[6] Y.Z. Chang, Xi'an university of architecture and technology, 2007 in Chinese.. 